\title{
Optimal Strategy of Triple Phase Shift Transient DC Bias for Dual Active Bridge DC-DC Converter
}

\author{
Jingyu Zhai ${ }^{1}$, Fusheng Wang ${ }^{1}$, Lizhong $\mathrm{Ye}^{2}$, Rui $\mathrm{Li}^{1}$ \\ ${ }^{1}$ School of Electrical and Automation Engineering, Hefei University of Technology, Hefei, 230009, China \\ ${ }^{2}$ Zhejiang Academy of Special Equipment Science, Hangzhou, 310020, China
}

\begin{abstract}
Under the traditional phase shift control, dual active bridge DC-DC converter (DAB) has a transient bias on the inductance current when the phase shift ratio changes suddenly, which leads to increase in the current stress of switch tubes and even unidirectional saturation of the transformer. All those will affect the stable operation of the converter. This paper focuses on quantifying the transient DC bias model on the control of triple phase shift when phase shift ratios change, and then the strategy proposed by the paper can eliminate the DC bias within one switching period and reduce current stress and response time by adjusting the drive signal during the transient transition process. Finally, the proposed strategy is verified by simulation results from Matlab/Simulink software.
\end{abstract}

\section{Introduction}

In recent years, with the development of renewable energy, it is necessary to use bidirectional DC-DC converters to achieve bidirectional energy transmission when the renewable energy power generation system and energy storage system are connected to the power grid[1]-[3]. The dual active bridge DC-DC converter (DAB) is a typical topology for bidirectional energy transmission. It has the advantage of electrical isolation, easy to achieve ZVS soft switching and high power density[4]-[6]. Naturally, DAB converters are commonly used in the fields of microgrid, energy storage system and new energy vehicles.

Figure 1 shows the topology of DAB converter. This converter is mainly composed of four parts: primary H-bridge, secondary H-bridge, high-frequency isolation transformer TF and inductance $\mathrm{L}_{\mathrm{r}}$. In DAB converter, the inductance $L_{r}$ acts as an energy storage and release element, and the power of converter is determined by the internal and external phase shift ratios of the primary and secondary sides. In the process of converter power regulation, the sudden change of phase shift ratios will cause an instantaneous current shock in the circuit, and DC bias will also appear at this moment. Current shock will cause the circuit current stress to increase, and the long-term DC bias may even cause deep saturation of the transformer in one direction, affecting the stable operation of the converter[7]-[8].

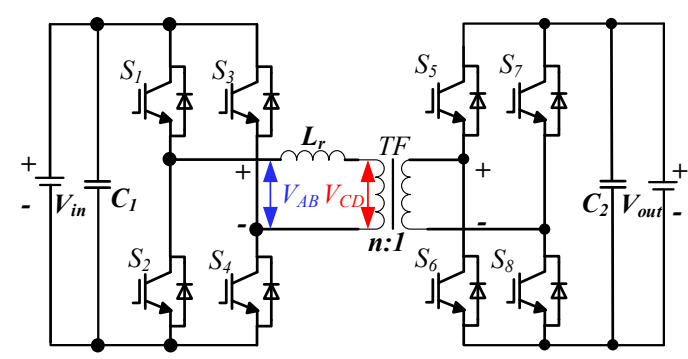

Figure 1. DAB converter topology

Triple phase shift (TPS) is the phase shift control with the highest degree of freedom. Single phase shift (SPS), extended phase shift (EPS) and dual phase shift (DPS) can be regarded as special cases of TPS. Therefore, this paper focuses on analyzing the converter under TPS control, through quantitative calculation to adjust the drive signal of the next period after phase shift ratios change, so that the converter can transition to the next stable state within one switching period after phase shift ratios change. This strategy can reduce current stress, eliminate DC bias and speed up dynamic response when phase shift ratios change.

\section{TPS control of DAB converter}

When the converter energy is transferred in the forward direction, the energy is transferred from the input side $V_{\text {in }}$ to the output side $V_{\text {out }}$; when the energy is transferred in the reverse direction, the energy is transferred from the output side $\mathrm{V}_{\text {out }}$ to the input side $\mathrm{V}_{\text {in }}$. In order to simplify the analysis process, this paper only analyzes the transient optimization strategy when the energy is 
transferred in the forward direction, and there is a similar analysis method when the energy is transferred in the reverse direction. As shown in Figure $1, \mathrm{~V}_{\mathrm{AB}}$ is the square wave voltage output by the primary H-bridge, and $\mathrm{V}_{\mathrm{CD}}$ is the square wave voltage output by the secondary $\mathrm{H}$-bridge and converted to the primary. $\mathrm{D}_{1}$ and $\mathrm{D}_{3}$ are defined as the internal phase shift ratios of the primary side and secondary side respectively, and $\mathrm{D}_{2}$ is the external phase shift ratio between primary side and secondary side.

When the converter energy is transferred in the forward direction, according to the relationship between $\mathrm{D}_{2}+\mathrm{D}_{3}$ and 1 , the steady working state of TPS can be divided into two types: when $\mathrm{D}_{2}+\mathrm{D}_{3}<1$, the converter is

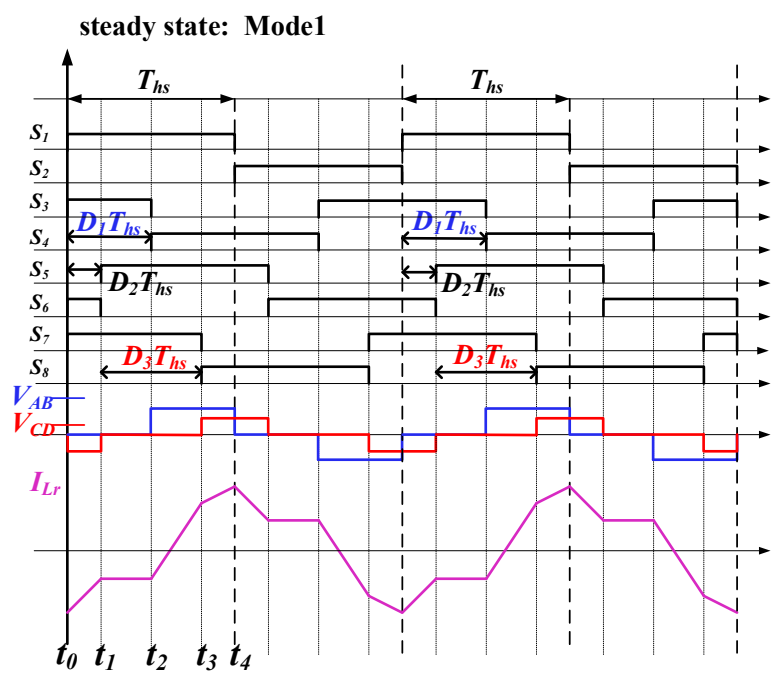

Figure 2. TPS steady state waveform in Mode 1

When the converter is in the steady state mode 2 , it also satisfies $I\left(t_{x}\right)=-I\left(t_{x}+T_{h s}\right)$. According to this condition, the current at the moment of the switching action within half a switching period can also be obtained, where the initial value of the current:

$$
I_{t 0}=-I_{t 4}=-\frac{V_{\text {in }}}{2 L}\left(-D_{1}+1\right) T_{h s}-\frac{n V_{\text {out }}}{2 L}\left(-D_{3}+1\right) T_{h s}
$$

\section{Transient DC bias phenomenon}

The sudden change of phase shift ratios will cause current shock and DC bias of the inductance current. In order to quantitatively calculate the DC bias of the inductance current, let the phase shift ratios before the change be $D_{1}, D_{2}, D_{3}$, and the phase shift ratios after the change are $D_{1}$ ", $D_{2}$ ", $D_{3}$ " respectively. If the maximum value of the inductance current after change is $I_{\max }$, the minimum value is $I_{\min }$, the transient DC bias is defined as $\mathrm{I}_{\mathrm{bias}}=0.5\left(\mathrm{I}_{\max }+\mathrm{I}_{\min }\right)$. The sudden change of phase shift ratios can be divided into the following four types considered to be in Mode 1, and its steady state operating waveform is shown in Figure 2; when $D_{2}+D_{3} \geq 1$, the converter is considered to be in Mode 2, and its steady state operating waveform is shown in Figure 3.

When the converter is in the steady state Mode 1 , it satisfies $I\left(t_{x}\right)=-I\left(t_{x}+T_{h s}\right)$, where $T_{h s}$ is half a switching period. According to this condition, the current at the moment of the switching action within half a switching period can be obtained, where the initial value of the current:

$$
I_{t 0}=-I_{t 4}=-\frac{V_{\text {in }}}{2 L}\left(-D_{1}+1\right) T_{h s}-\frac{n V_{\text {out }}}{2 L}\left(2 D_{2}+D_{3}-1\right) T_{h s}
$$

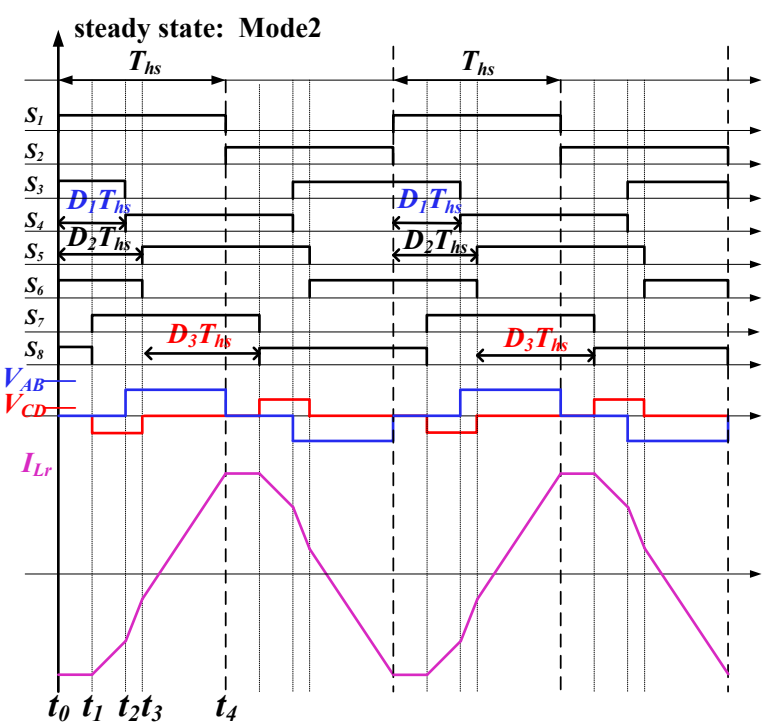

Figure 3. TPS steady state waveform in Mode 2

because the steady state under TPS control is divided into two types.

Transient DC bias $\mathrm{I}_{\text {bias }}$ under various conditions:

$$
\begin{aligned}
& I_{\text {bias }} 1-1=\frac{I_{t 0} "+I_{t 4} "}{2}=\frac{V_{\text {in }}}{2 L}\left(D_{1}-D_{1} "\right) T_{h s}+\frac{n V_{\text {out }}}{2 L}\left(-2 D_{2}+2 D_{2} "-D_{3}+D_{3} "\right) T_{h s} \\
& I_{\text {bias }} 1-2=\frac{I_{t 0}{ }^{\prime \prime}+I_{t 4} "}{2}=\frac{V_{\text {in }}}{2 L}\left(D_{1}-D_{1} "\right) T_{h s}+\frac{n V_{\text {out }}}{2 L}\left(-2 D_{2}+2 D_{2} "-D_{3}+D_{3} "\right) T_{h s} \\
& I_{\text {bias }} 2-1=\frac{I_{t 0}{ }^{\prime \prime}+I_{t 4} "}{2}=\frac{V_{\text {in }}}{2 L}\left(D_{1}-D_{1} "\right) T_{h s}+\frac{n V_{\text {out }}}{2 L}\left(D_{3}-D_{3} "-2\right) T_{h s} \\
& I_{\text {bias }} 2-2=\frac{I_{t 0}{ }^{\prime \prime}+I_{t 4} "}{2}=\frac{V_{\text {in }}}{2 L}\left(D_{1}-D_{1} "\right) T_{h s}+\frac{n V_{\text {out }}}{2 L}\left(D_{3}-D_{3} "\right) T_{h s}
\end{aligned}
$$

After phase shift ratios change, the inductance current $\mathrm{I}_{\mathrm{Lr}}$ exhibits asymmetry between positive and negative, $\mathrm{I}_{\text {bias }} \neq 0$, which is called transient DC bias. Long-term DC bias will cause transformer unidirectional magnetic saturation. At the moment of change, current shock will also occur, which will endanger the safe operation of the converter. 


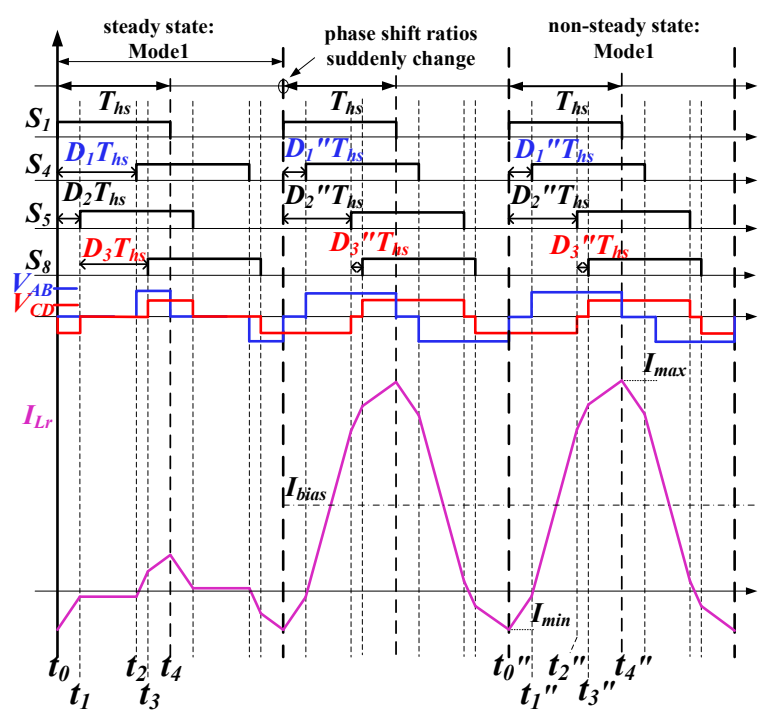

Figure 4. Mode 1 before and after change, without transient optimization strategy

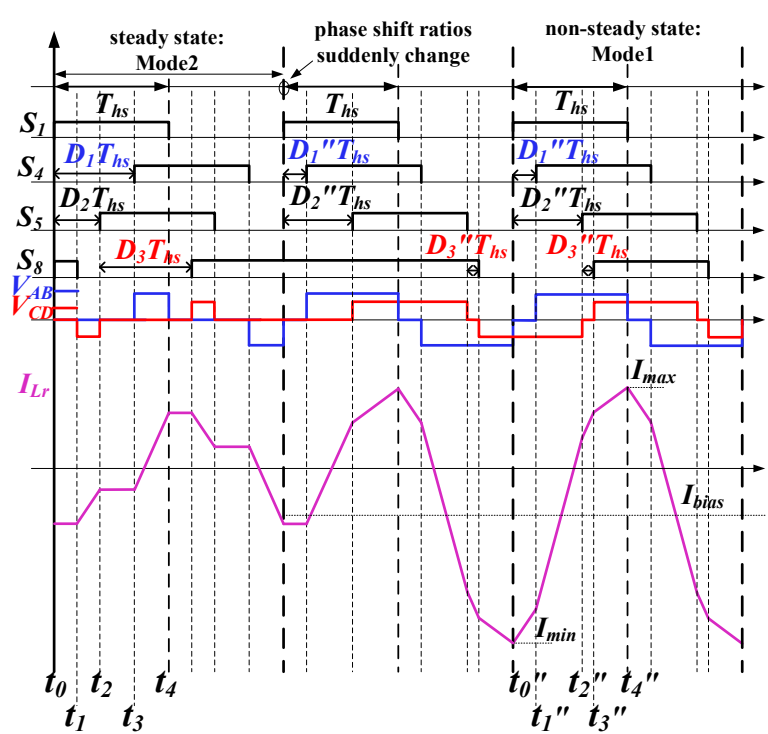

Figure 6. Mode 2 before change and Mode 1 after change, without transient optimization strategy

\section{Optimized control strategy for transient DC bias}

After optimization, let the phase shift ratios before change be $D_{1}, D_{2}, D_{3}$, and the converter is considered to be in steady state 1; let the phase shift ratios after change be $\mathrm{D}_{1}$ ", $\mathrm{D}_{2}$ ", $\mathrm{D}_{3}$ ", and the converter is considered to be in

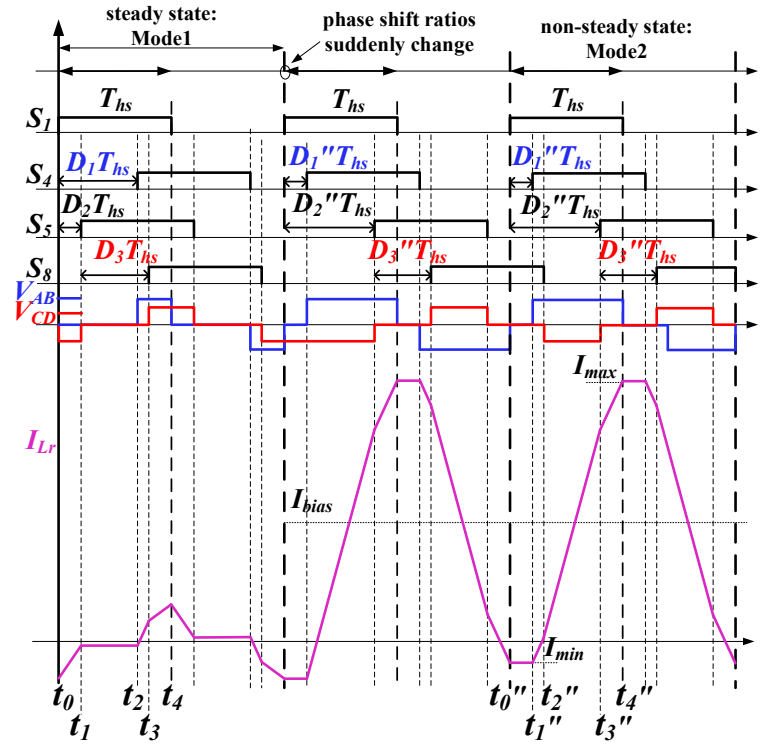

Figure 5. Mode 1 before change and Mode 2 after change, without transient optimization strategy

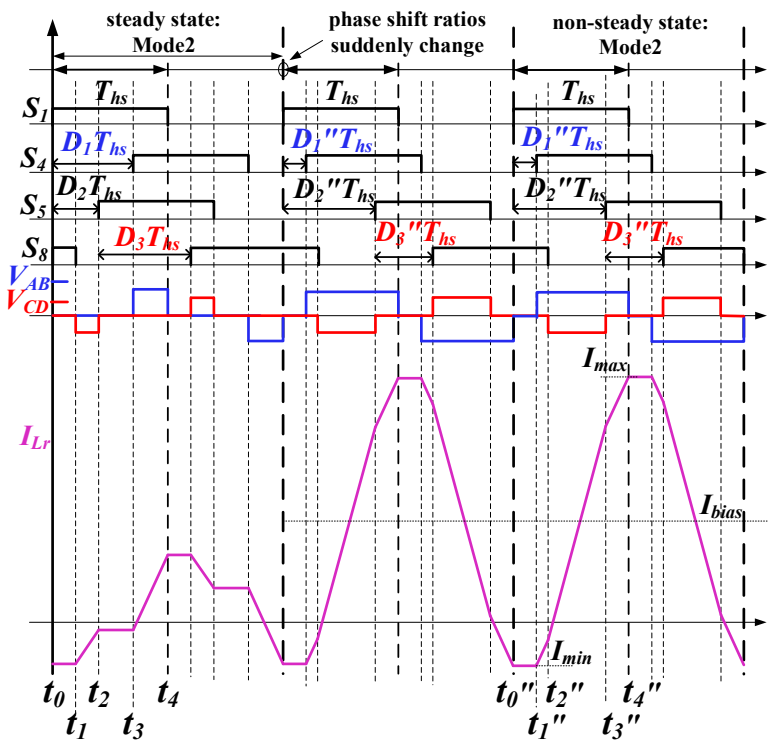

Figure 7. Mode 2 before and after change, without transient optimization strategy

steady state 2 . The moment between steady state 1 and steady state 2 is called transient transition process. In the following, we can quantitatively adjust the turn-on and turn-off moments of drive signal during the transient transition process by setting an unknown quantity to solve, in order to eliminate transient DC bias within one switching period. 


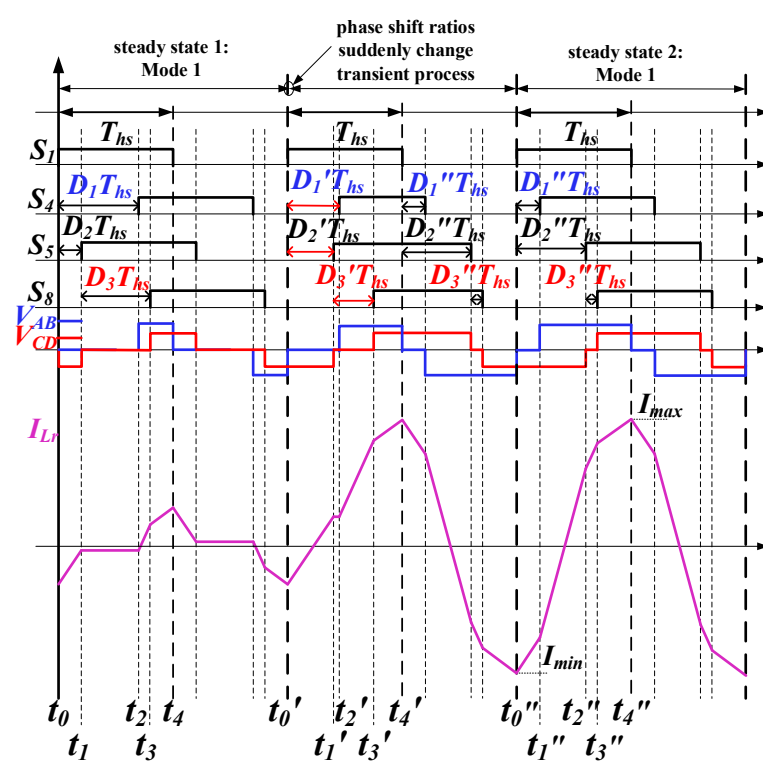

Figure 8. Mode 1 before and after change, with transient optimization strategy

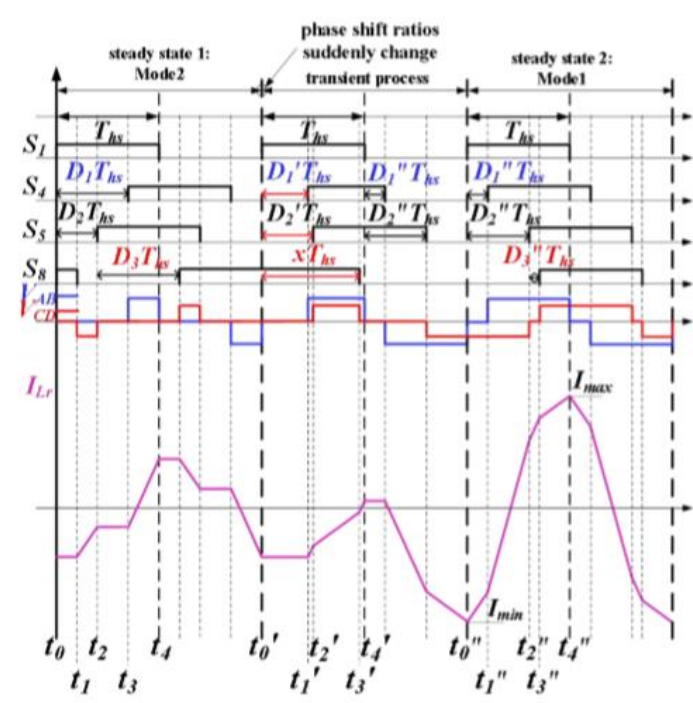

Figure 10. Mode 2 before change and Mode 1 after change, with transient optimization strategy

\subsection{Mode 1 before and after change}

As shown in Figure 8, assuming that the drive signal of the 4,5 , and 8 tubes are turned on at the time of $\mathrm{D}_{1}{ }^{\prime} \mathrm{T}_{\mathrm{hs}}$, $\mathrm{D}_{2}{ }^{\prime} \mathrm{T}_{\mathrm{hs}},\left(\mathrm{D}_{2}{ }^{\prime}+\mathrm{D}_{3}{ }^{\prime}\right) \mathrm{T}_{\mathrm{hs}}$, and the turn-off time is the same as steady state 2 during transient transition process, the converter can eliminate transient $\mathrm{DC}$ bias. Through $\mathrm{I}_{\mathrm{t} 0}$ and the set value of the transient transition process, we can obtain:

$I_{t 4}{ }^{\prime}=\frac{V_{\text {in }}}{2 L}\left(D_{1}-2 D_{1}{ }^{\prime}+1\right) T_{h s}+\frac{n V_{\text {out }}}{2 L}\left(-2 D_{2}+4 D_{2}{ }^{\prime}-D_{3}+2 D_{3}{ }^{\prime}-1\right) T_{h s}$

Since the second half of the transient transition process is exactly the same as the second half of the

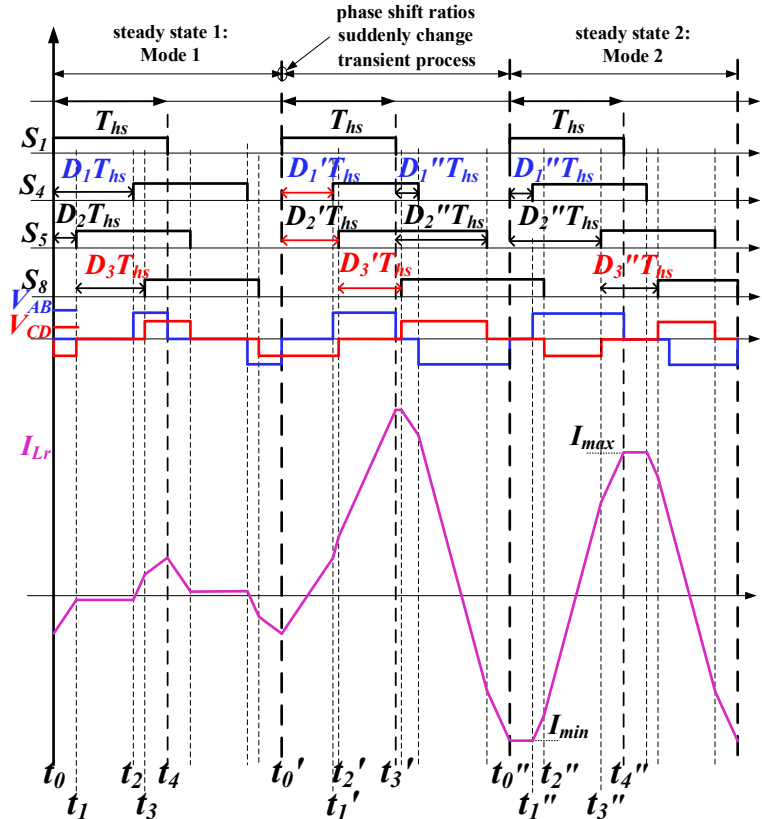

Figure 9. Mode 1 before change and Mode 2 after change, with transient optimization strategy

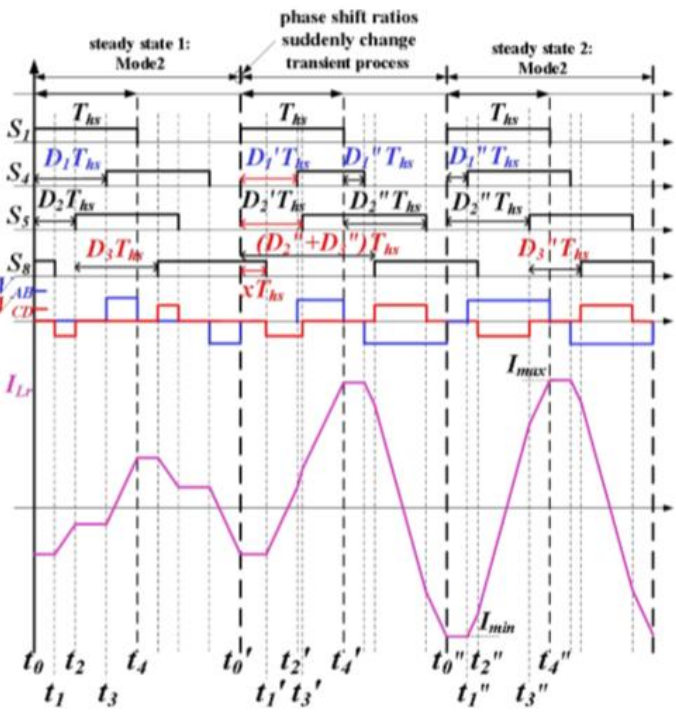

Figure 11. Mode 2 before and after change, with transient optimization strategy

steady state afterwards, so:

$I_{t 4}{ }^{\prime}=-I_{t 0}{ }^{\prime \prime}=\frac{V_{\text {in }}}{2 L}\left(-D_{1}{ }^{\prime}+1\right) T_{h s}+\frac{n V_{\text {out }}}{2 L}\left(2 D_{2} "+D_{3} "-1\right) T_{h s}$

Combining (4)、(5), we can get:

$D_{1}{ }^{\prime}=0.5\left(D_{1}+D_{1}{ }^{\prime \prime}\right) ; 2 D_{2}{ }^{\prime}+D_{3}{ }^{\prime}=\left(D_{2}+D_{2}{ }^{\prime \prime}\right)+0.5\left(D_{3}+D_{3}{ }^{\prime \prime}\right)$

If $\mathrm{D}_{2}{ }^{\prime}=0.5\left(\mathrm{D}_{2}+\mathrm{D}_{2}{ }^{\prime \prime}\right)$, then $\mathrm{D}_{3}{ }^{\prime}=0.5\left(\mathrm{D}_{3}+\mathrm{D}_{3}{ }^{\prime \prime}\right)$.

\subsection{Mode 1 before change, Mode 2 after change}

As shown in Figure 9, assuming that the drive signal of the 4,5 and 8 tubes are turned on at the time of $\mathrm{D}_{1}{ }^{\prime} \mathrm{T}_{\mathrm{hs}}$, $\mathrm{D}_{2}{ }^{\prime} \mathrm{T}_{\mathrm{hs}},\left(\mathrm{D}_{2}{ }^{\prime}+\mathrm{D}_{3}{ }^{\prime}\right) \mathrm{T}_{\mathrm{hs}}$, , and the turn-off time of the 4 and 
5 tube is the same as steady state 2 during transient transition process, the converter can eliminate transient DC bias. Through $\mathrm{I}_{\mathrm{t} 0}$ and the set value of the transient transition process, we can obtain:

$$
I_{t 0}{ }^{\prime \prime}=\frac{V_{\text {in }}}{2 L}\left(D_{1}-2 D_{1}{ }^{\prime}+2 D_{1}{ }^{\prime \prime}-1\right) T_{h s}+\frac{n V_{\text {out }}}{2 L}\left(-2 D_{2}+4 D_{2}{ }^{\prime}-2 D_{2}{ }^{\prime \prime}-D_{3}+2 D_{3}{ }^{\prime}-1\right) T_{h s}
$$

$\mathrm{I}_{\mathrm{t} 0}$ " itself can be solved by the steady state process afterwards:

$$
I_{t 0} "=-\frac{V_{\text {in }}}{2 L}\left(-D_{1} "+1\right) T_{h s}-\frac{n V_{\text {out }}}{2 L}\left(-D_{3} "+1\right) T_{h s}
$$

Combining (7)、(8),we can get:

$D_{1}{ }^{\prime}=0.5\left(D_{1}+D_{1}{ }^{\prime \prime}\right) ; 2 D_{2}{ }^{\prime}+D_{3}{ }^{\prime}=\left(D_{2}+D_{2}{ }^{\prime \prime}\right)+0.5\left(D_{3}+D_{3}{ }^{\prime \prime}\right)$

If $\mathrm{D}_{2}{ }^{\prime}=0.5\left(\mathrm{D}_{2}+\mathrm{D}_{2}{ }^{\prime \prime}\right)$, then $\mathrm{D}_{3}{ }^{\prime}=0.5\left(\mathrm{D}_{3}+\mathrm{D}_{3}{ }^{\prime \prime}\right)$.

\subsection{Mode 2 before change and Mode 1 after change}

As shown in Figure 10, assuming that the drive signal of the 4 and 5 tubes are turned on at the time of $\mathrm{D}_{1}{ }^{\prime} \mathrm{T}_{\mathrm{hs}}$, $\mathrm{D}_{2}{ }^{\prime} \mathrm{T}_{\mathrm{hs}}$, and the turn-off time is the same as steady state 2 , and the turn-off time of tube 8 is $\mathrm{xT}_{\mathrm{hs}}$ during transient transition process, the converter can eliminate transient DC bias. Through $\mathrm{I}_{\mathrm{t} 0}$ and the set value of the transient transition process, we can obtain:

$$
I_{t 0} "=\frac{V_{\text {in }}}{2 L}\left(D_{1}-2 D_{1}{ }^{\prime}+2 D_{1} "-1\right) T_{h s}+\frac{n V_{\text {out }}}{2 L}\left(2 D_{2}{ }^{\prime}-2 D_{2}{ }^{\prime \prime}+D_{3}+1-2 x\right) T_{h s}
$$

$\mathrm{I}_{\mathrm{t} 0}$ " itself can be solved by the steady state process afterwards:

$$
I_{t 0} "=-\frac{V_{\text {in }}}{2 L}\left(-D_{1} "+1\right) T_{h s}-\frac{n V_{\text {out }}}{2 L}\left(2 D_{2} "+D_{3}^{\prime \prime}-1\right) T_{h s}
$$

Combining (10)、(11),we can get:

$$
\begin{aligned}
& D_{1}{ }^{\prime}=0.5\left(D_{1}+D_{1}{ }^{\prime}\right) ; x=D_{2}{ }^{\prime}+0.5\left(D_{3}+D_{3}{ }^{\prime \prime}\right) \\
& \text { If } \mathrm{D}_{2}{ }^{\prime}=0.5\left(\mathrm{D}_{2}+\mathrm{D}_{2}{ }^{\prime \prime}\right) \text {, then } \\
& D_{1}{ }^{\prime}=0.5\left(D_{1}+D_{1}{ }^{\prime \prime}\right) ; x=0.5\left(D_{2}+D_{2}{ }^{\prime \prime}\right)+0.5\left(D_{3}+D_{3}{ }^{\prime \prime}\right)
\end{aligned}
$$

\subsection{Mode 2 before and after change}

As shown in Figure 11, assuming that the drive signal of the 4 and 5 tubes are turned on at the time of $\mathrm{D}_{1}{ }^{\prime} \mathrm{T}_{\mathrm{hs}}$, $\mathrm{D}_{2}{ }^{\prime} \mathrm{T}_{\mathrm{hs}}$, and the turn-off time is the same as steady state 2 , and the turn-on time of tube 8 is the same as steady state 2 , and the turn-off time is $\mathrm{xT}_{\mathrm{hs}}$ during transient transition process, the converter can eliminate transient DC bias. Through $\mathrm{I}_{\mathrm{t} 0}$ and the set value of the transient transition process, we can obtain:

$I_{t 0}{ }^{\prime \prime}=\frac{V_{\text {in }}}{2 L}\left(D_{1}-2 D_{1}{ }^{\prime}+2 D_{1}^{\prime \prime}-1\right) T_{h s}+\frac{n V_{\text {out }}}{2 L}\left(2 D_{2}{ }^{\prime}+D_{3}+2 D_{3}{ }^{\prime \prime}-3-2 x\right) T_{h s}$

$\mathrm{I}_{\mathrm{t} 0}$ " itself can be solved by the steady state process afterwards:

$$
I_{t 0} "=-\frac{V_{\text {in }}}{2 L}\left(-D_{1} "+1\right) T_{h s}-\frac{n V_{\text {out }}}{2 L}\left(-D_{3} "+1\right) T_{h s}
$$

Combining (14)、(15),we can get:

$$
\begin{aligned}
& D_{1}{ }^{\prime}=0.5\left(D_{1}+D_{1}{ }^{\prime}\right) ; x=D_{2}{ }^{\prime}+0.5\left(D_{3}+D_{3}{ }^{\prime \prime}\right)-1 \\
& \text { If } \mathrm{D}_{2}{ }^{\prime}=0.5\left(\mathrm{D}_{2}+\mathrm{D}_{2}{ }^{\prime \prime}\right) \text {, then } \\
& D_{1}{ }^{\prime}=0.5\left(D_{1}+D_{1}{ }^{\prime \prime}\right) ; x=0.5\left[\left(D_{2}+D_{2}{ }^{\prime \prime}\right)+\left(D_{3}+D_{3}{ }^{\prime \prime}\right)\right]-1
\end{aligned}
$$

In the four cases discussed, we can eliminate the transient DC bias by adjusting the turn-on and turn-off time of the switch tube respectively during the transient transition process.

\section{Simulation verification}

In order to verify the transient optimization control strategy proposed for TPS, this paper uses Matlab/simulation software to verify the idea. The simulation parameters are shown in Table 1.

Table 1. Main parameters of the simulation

\begin{tabular}{cc}
\hline parameter & value \\
\hline Input voltage & $640 \mathrm{~V}$ \\
Output voltage & $26.67 \mathrm{~V}$ \\
Resonant inductance & $28.5 \mathrm{uH}$ \\
Switch frequency & $100 \mathrm{KHz}$ \\
Transformer ratio & $8: 1$ \\
\hline
\end{tabular}

\subsection{Mode 1 before and after change}

The simulation conditions of Figure 12: the transition is from $\mathrm{D}_{1}=0.7, \mathrm{D}_{2}=0.2, \mathrm{D}_{3}=0.6$ of Mode 1 to $\mathrm{D}_{1}=0.2$, $\mathrm{D}_{2}=0.6, \mathrm{D}_{3}=0.1$ of Mode 1 .

\subsection{Mode 1 before change, Mode 2 after change}

The simulation conditions of Figure 13: the transition is from $\mathrm{D}_{1}=0.7, \mathrm{D}_{2}=0.2, \mathrm{D}_{3}=0.6$ of Mode 1 to $\mathrm{D}_{1}=0.2$, $\mathrm{D}_{2}=0.8, \mathrm{D}_{3}=0.5$ of Mode 2 . 

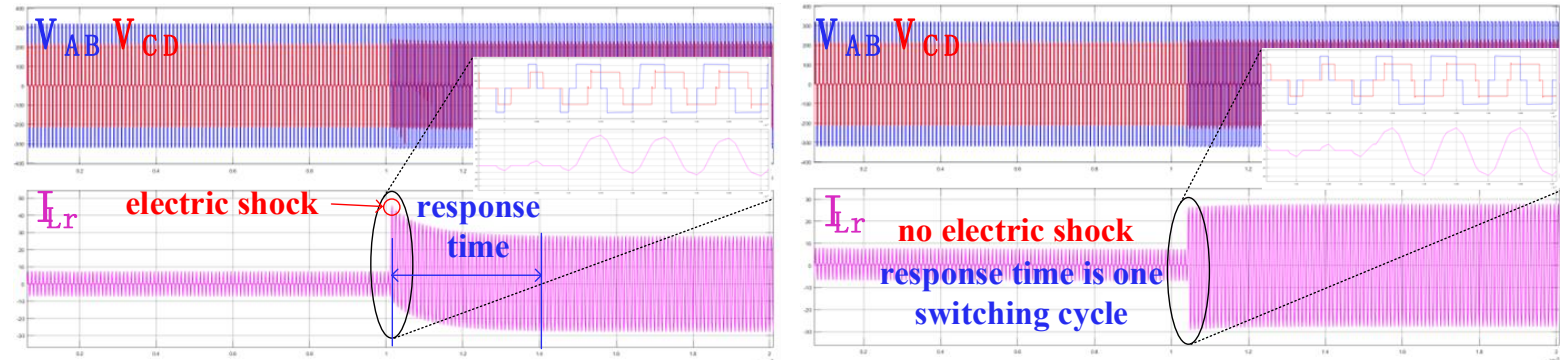

Figure 12. Mode 1 before and after change (a)without optimization strategy (b)with optimization strategy
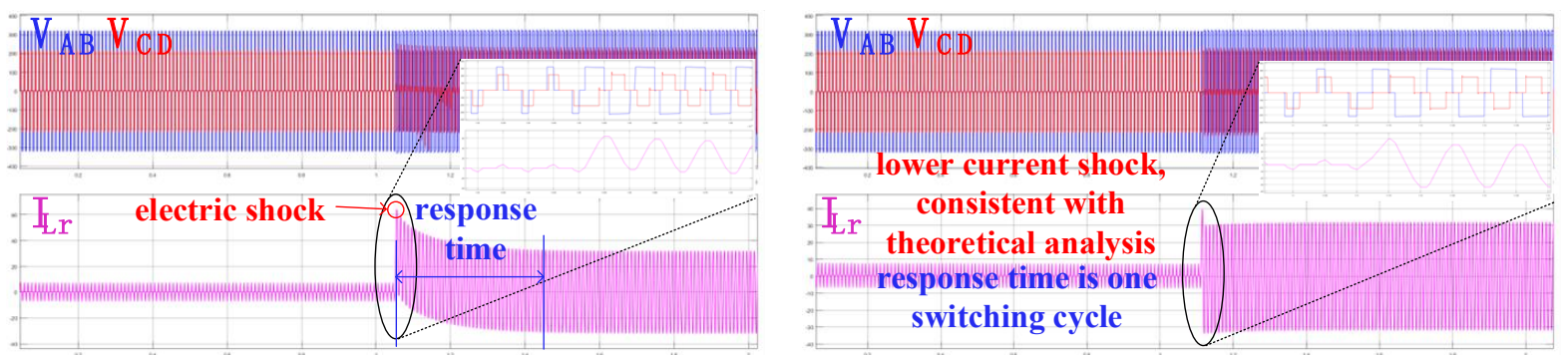

Figure 13. Mode 1 before change, Mode 2 after change (a)without optimization strategy (b)with optimization strategy
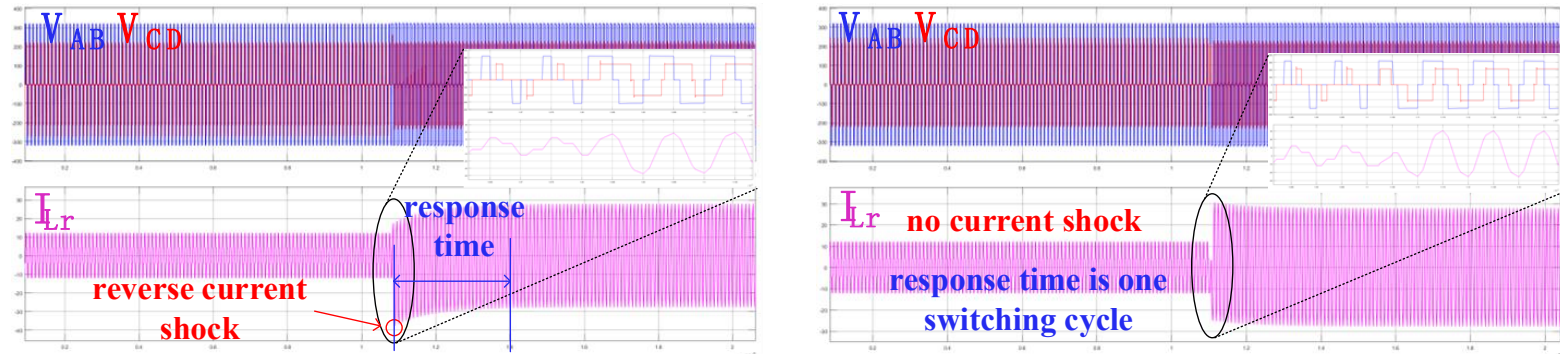

Figure 14. Mode 2 before change, Mode 1 after change (a)without optimization strategy (b)with optimization strategy
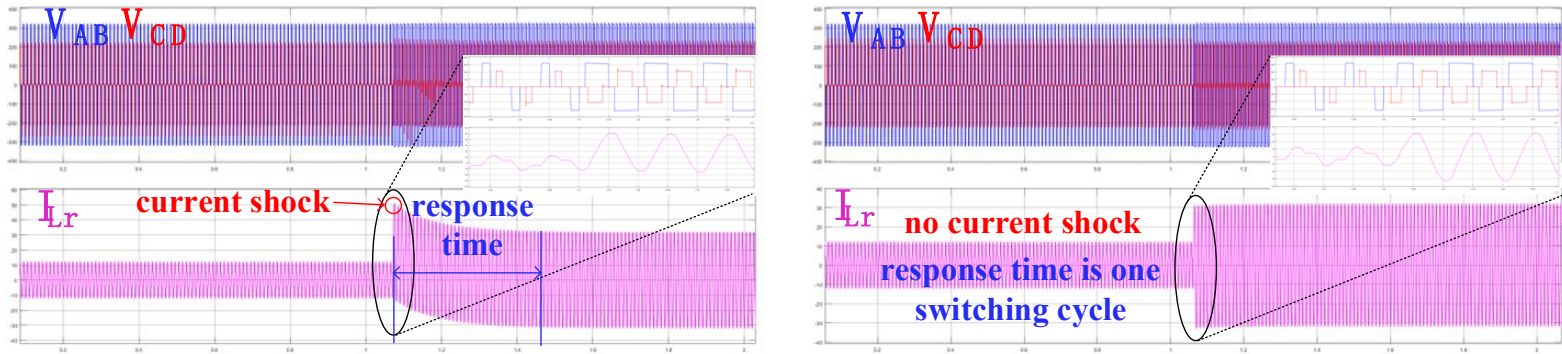

Figure 15. Mode 2 before and after change (a)without optimization strategy (b)with optimization strategy

\subsection{Mode 2 before change, Mode 1 after change}

The simulation conditions in Figure 14: the transition is from $\mathrm{D}_{1}=0.7, \mathrm{D}_{2}=0.4, \mathrm{D}_{3}=0.8$ of Mode 2 to $\mathrm{D}_{1}=0.2$, $\mathrm{D}_{2}=0.6, \mathrm{D}_{3}=0.1$ of Mode 1 .

\subsection{Mode 2 before and after change}

The simulation conditions of Figure 15: the transition is from $\mathrm{D}_{1}=0.7, \mathrm{D}_{2}=0.4, \mathrm{D}_{3}=0.8$ of Mode 2 to $\mathrm{D}_{1}=0.2$, $\mathrm{D}_{2}=0.8, \mathrm{D}_{3}=0.5$ of Mode 2 .

From the simulation results, a larger current shock will be generated at the moment of phase shift ratios change and the response time is longer when the converter does not have a transient optimization strategy. When the transient optimization strategy exists, the stable state is restored within a switching period after phase shift ratios change. This optimization strategy reduces the transient DC bias and current shock caused by the sudden change of phase shift ratios, and speeds up the dynamic response.

\section{Conclusion}

In this paper, a transient optimization strategy under the control of TPS with dual active bridge DC-DC converters is proposed by classifying the TPS control strategy. The main idea of this strategy is to adjust the moment when the drive signal is turned on and off during the transient transition process, so that the current can be adjusted from the initial value of steady state 1 to the initial value of steady state 2 . We can solve the specific moment by setting the unknown quantity. This strategy 
can reduce current shock and transient DC bias of the converter and speed up the dynamic response after phase shift ratios change.

\section{References}

1. Y. Wang, F. Qin and Y. Kim. (2014) Bidirectional DC-DC Converter Design and Implementation for Lithium-ion Battery Application. In: Asia-Pacific Power and Energy Engineering Conference (APPEEC), HongKong. pp. 1-5.

2. Z. Tao and L. Li. (2017) Control Loop Design and Bidirectional Control Strategy of a Bidirectional DC/DC Converter. In: IECON 2017 - 43rd Annual Conference of the IEEE Industrial Electronics Society, Beijing. pp. 5720-5725.

3. N. A. Dung, H. Hsieh, J. Lin, H. Chiu and J. Lai. (2019) Design of Bidirectional DC-DC Converter for Energy Storage System in High Power Application. In: 2019 IEEE 4th International Future Energy Electronics Conference (IFEEC), Singapore. pp. 1-4.

4. C. Song, A. Chen, J. Chen, C. Du and C. Zhang. (2018) Optimized Modulation Scheme for Dual Active Bridge DC-DC Converter. In: 2018 IEEE Applied Power Electronics Conference and Exposition (APEC), San Antonio. pp. 3569-3574.

5. Weijian Han, Ruiqing Ma, Qing Liu and L. Corradini. (2016) A Conduction Losses Optimization Strategy for DAB Converters in Wide Voltage Range. In: IECON 2016-42nd Annual Conference of the IEEE Industrial Electronics Society, Florence. pp.2445-2451.

6. L. Jin, B. Liu and S. Duan. (2017) ZVS Operation Range Analysis of Three-level Dual Active Bridge DC-DC Converter with Phase-shift Control. In: 2017 IEEE Applied Power Electronics Conference and Exposition (APEC), Tampa, pp. 362-366.

7. C. Sun and X. Li. (2018) Instantaneous Current Balance Modulation for Fast Transient Response in a Dual-Active-Bridge Converter. In: 2018 IEEE International Power Electronics and Application Conference and Exposition (PEAC), Shenzhen. pp. 1-6.

8. T. Dai et al. (2020) Research on Transient DC Bias Analysis and Suppression in EPS DAB DC-DC Converter. IEEE Access, 8: 61421-61432. 